\title{
TÉCNICAS DE AVALIAÇÃo DA RESISTÊNCIA DE AMEIXEIRA À Xanthomonas arboricola pv pruni ${ }^{1}$
}

\author{
IDEMIR CITADIN ${ }^{2}$, MARCELO HENRIQUE BASSANI ${ }^{3}$, IDALMIR DOS SANTOS ${ }^{4}$, SÉRGIO MIGUEL MAZARO4, \\ MARIA DO CARMO BASSOLS RASEIRA ${ }^{5}$, MOESES ANDRIGO DANNER ${ }^{2}$
}

\begin{abstract}
RESUMO - A bacteriose da ameixeira e de outras frutíferas de caroço, causada pela bactéria Xanthomonas arboricola pv. pruni (Smith), é uma doença grave em climas quentes e úmidos. O controle químico é oneroso, de baixa eficiência e danoso ao meio ambiente. Por outro lado, em áreas de ocorrência da doença, o uso de cultivares resistentes é muito importante, dentro de um programa de manejo, para reduzir os riscos de perdas. Porém, a seleção de genótipos resistentes tem sido dificultada pela ausência de métodos rápidos e eficientes de avaliar a doença nas plantas, especialmente nas folhas e ramos. O objetivo deste trabalho foi testar diferentes técnicas de avaliação da intensidade da bacteriose em folhas e ramos de ameixeira e classificar as cultivares Amarelinha, XV de Novembro e Irati quanto ao grau de resistência à X. arboricola pv. pruni. Das técnicas de avaliação utilizadas, a severidade da doença nas folhas foi mais eficiente que o número médio de lesões por folha. Para os ramos, as técnicas que consideram o número de cancros por metro linear e o número médio de cancros dos $10 \mathrm{~cm}$ da base dos ramos eficientes. Porém, esta última tem a vantagem de ser mais rápida e facilmente empregada. Das cultivares avaliadas, 'Irati' apresentou maior resistência.
\end{abstract}

Termos para indexação: Prunus salicina, fruteiras de caroço, resistência a doenças, melhoramento de fruteiras.

\section{SCREENING TECHNIQUES FOR BACTERIAL SPOT (Xanthomonas arboricola pv pruni) RESISTANCE IN JAPANESE-TYPE PLUM CULTIVARS}

\begin{abstract}
Bacterial spot of Japanese-type plum and others stone seed fruits, caused by Xanthomonas arboricola pv. pruni, is a serious disease in warm and humid environments. Chemical control is costly and often ineffective. Therefore, in areas where bacterial spot is a problem, the use of resistant cultivars is an important part of a management program for reducing the risk of loss from this disease. However, the selection of resistant genotypes is difficult because there are no rapid and reliable methods to evaluate the severity of disease on leaves and twigs. The aim of this work was to test screening techniques to identify resistant genotypes under field conditions and to classify three Japanese plum varieties according to their reaction to bacterial spot. Among the screening techniques compared, leaf severity was more reliable than the mean number of leaf spots. The number of twig cankers per meter and the mean of cankers in the first $10 \mathrm{~cm}$ from the twig base were both reliable, but the last technique is faster and easier to apply. 'Irati' exhibited the highest level of resistance, among the other cultivars.
\end{abstract}

Index Terms: Prunus salicina, stone seed fruits, disease resistance, stone seed fruits breeding.

\section{INTRODUÇÃO}

A bacteriose da ameixeira e de outras frutíferas de caroço é causada pela bactéria Xanthomonas arboricola pv. pruni (Smith). A doença é favorecida por clima quente e úmido durante o crescimento vegetativo das prunóideas, condições típicas das regiões produtoras do Brasil (Feliciano, 1973; Mohan et al., 1977; Nogueira \& Rodrigues Neto, 1982). A doença expressa-se nas folhas por manchas aquosas, pardas ou púrpuras, que secam e caem, causando perfurações ao longo do limbo, com conseqüente desfolha prematura. Pode ainda manifestarse por cancros de primavera e verão nos ramos e por manchas nos frutos, que coalescem provocando rachaduras. Os frutos infectados são indesejáveis para o processamento, devido à dificuldade de remoção das lesões que atingem a polpa, e para o consumo in natura, por terem a aparência comprometida, perdendo o valor comercial (Fortes \& Martins, 1998)

As alternativas disponíveis para reduzir os prejuízos decorrentes da doença são a utilização de quebra-ventos, o controle químico e o uso de cultivares resistentes. Porém, o controle químico tem sido insatisfatório, principalmente em anos ou locais onde ocorrem condições favoráveis ao desenvolvimento da doença, além de ser danoso ao meio ambiente. Isto faz com que o uso de cultivares que tenham algum nível de resistência, seja vantajoso. Não existem cultivares imunes, principalmente em condições favoráveis para o surgimento da doença. Porém, existe uma grande variação no nível de resistência entre cultivares desta espécie ou entre outras espécies de Prunus (Keil \& Fogle, 1974; Rom \& Moore, 1979; Werner et al. 1986). Em áreas onde a bacteriose da ameixeira é um problema, o uso de cultivares resistentes é muito importante, dentro de um programa de manejo, para reduzir as perdas pela enfermidade.

A seleção de genótipos resistentes tem sido dificultada pela ausência de métodos rápidos e eficientes de avaliar a doença nas plantas, principalmente quando estas se encontram em estádio juvenil, e pela falta de uma definição clara se existe correlação da resistência nos diferentes estádios de desenvolvimento das plantas e entre folhas, ramos e frutos (Keil \& Fogle, 1974; Werner et al., 1986). Amorim (1995) destaca a importância de se definir e/ou diferenciar claramente incidência e severidade de doenças. Este conhecimento é a base para a elaboração de técnicas de avaliação de doenças que visem a identificar genótipos resistentes.

O objetivo deste trabalho foi testar diferentes técnicas de avaliação da intensidade da doença em folhas e ramos de ameixeira e classificar as cultivares Amarelinha, XV de Novembro e Irati quanto ao nível de resistência à $X$. arboricola pv. pruni.

\section{MATERIALE MÉTODOS}

O trabalho foi conduzido no pomar experimental do Centro Federal de Educação Tecnológica do Paraná (CEFET-PR), localizado no município de Pato Branco, com coordenadas geográficas de $26^{\circ} 56^{\prime}$ de Latitude Sul, 52 $86^{\circ}$ 'Longitude Oeste e 700 metros de altitude. Além de o pomar não possuir quebra-vento, o que facilita a infestação por Xanthomonas, também não foram feitas aplicações com antibióticos. Os demais tratos culturais foram efetuados de acordo com a necessidade da cultura. A incidência e a severidade da bacteriose foram avaliadas em folhas, no ano de 2002, e em ramos, nos anos de 2001 e 2003, nas cultivares Amarelinha, XV de Novembro e Irati, avaliando-se os seguintes parâmetros:

\footnotetext{
${ }^{1}$ (Trabalho 079/2005). Recebido: 06/05/2005. Aceito para publicação: 06/10/2005.

2 Eng. Agrônomo, Doutor, Professor CEFET-PR - Unidade Sudoeste. Idemir@pb.cefetpr.br

${ }^{3}$ Acadêmicos de Agronomia - CEFET-PR, Bolsistas de Iniciação Científica.

${ }^{4}$ Eng. Agrônomo, Mestre, Professor, CEFET-PR - Unidade Sudoeste.

${ }^{5}$ Eng $^{\mathrm{a}}$ Agrônoma, PhD, Embrapa Clima Temperado.
} 
TABELA 1 - Incidência e severidade da bacteriose de ameixeira (Xanthomonas arboricola pv. pruni), avaliada em folhas e ramos. CEFET-PR, Pato Branco, 2004.

\begin{tabular}{|c|c|c|c|c|c|c|c|c|}
\hline \multirow[t]{2}{*}{ Cultivar } & \multirow{2}{*}{$\begin{array}{l}N^{0} \text { médio de lesões por } \\
\text { folha } \\
2002\end{array}$} & \multirow{2}{*}{$\begin{array}{l}\begin{array}{l}\text { Severidade média } \\
\text { da doença }(\%)\end{array} \\
2002\end{array}$} & \multicolumn{2}{|c|}{$\begin{array}{l}\mathrm{N}^{0} \text { médio de cancros nos } \\
10 \mathrm{~cm} \text { da base dos ramos }\end{array}$} & \multicolumn{2}{|c|}{$\begin{array}{l}\mathrm{N}^{\circ} \text { médio de cancros } \\
\text { por metro de ramos }\end{array}$} & \multicolumn{2}{|c|}{$\begin{array}{l}\text { Tamanho médio dos três } \\
\text { maiores cancros }(\mathrm{cm})\end{array}$} \\
\hline & & & 2001 & 2003 & 2001 & 2003 & 2001 & 2003 \\
\hline Amarelinha & $15,7 \mathrm{a}^{*}$ & $5,52 \mathrm{a}$ & $2,73 \mathrm{a}$ & $0,88 \mathrm{a}$ & $7,3 \mathrm{a}$ & $5,6 \mathrm{a}$ & $1,39 \mathrm{a}$ & $1,47 \mathrm{a}$ \\
\hline XV Novembro & $5,9 \mathrm{c}$ & $4,83 \mathrm{a}$ & $1,43 \mathrm{~b}$ & $0,22 \mathrm{~b}$ & $5,4 \mathrm{~b}$ & $3,5 \mathrm{~b}$ & $1,21 \mathrm{~b}$ & $1,10 \mathrm{~b}$ \\
\hline Irati & $9,2 \mathrm{~b}$ & $3,08 \mathrm{~b}$ & $0,36 \mathrm{c}$ & $0,20 \mathrm{~b}$ & $3,0 \mathrm{c}$ & $2,4 \mathrm{c}$ & $1,05 \mathrm{c}$ & $1,03 \mathrm{~b}$ \\
\hline $\mathrm{CV}(\%)$ & 13,9 & 7,5 & 16,6 & 12,3 & 18,1 & 19,4 & 5,8 & 7,37 \\
\hline
\end{tabular}

*Médias seguidas de mesma letra minúscula na coluna não diferem pelo teste de Duncan $(P d$ " 0,05$)$.

a. Número de lesões por folha. Foram sorteadas dez plantas de cada cultivar e de cada planta foram coletadas 50 folhas distribuídas ao longo de todo o perímetro, em meados de janeiro de 2002. Em laboratório, procedeu-se a contagem do número de lesões por folha, calculando-se, posteriormente, a média de lesões por folha para cada planta. O delineamento experimental empregado foi o inteiramente casualizado, com três tratamentos (cultivares) e 10 repetições (plantas/cultivar).

b. Severidade da doença na folha. Foram sorteadas seis plantas de cada cultivar, e de cada planta foram coletadas 50 folhas distribuídas ao longo de todo o perímetro, em meados de janeiro de 2002. A avaliação da severidade da doença foi baseada na escala diagramática proposta por Topp et al. (1991).

c. Número de cancros nos $10 \mathrm{~cm}$ da base dos ramos do ano. Durante o período de repouso das plantas (julho/2001 e 2003), foram coletados 10 ramos do ano por planta, fazendo-se a contagem do número de cancros nos primeiros $10 \mathrm{~cm}$ a partir da base, calculando-se a média por planta. Cada cultivar foi representada por um número diferente de repetições em 2001, sendo que para 'Irati' foram coletados ramos em 23 plantas, para 'XV de Novembro' em 42 plantas e para 'Amarelinha' em

A
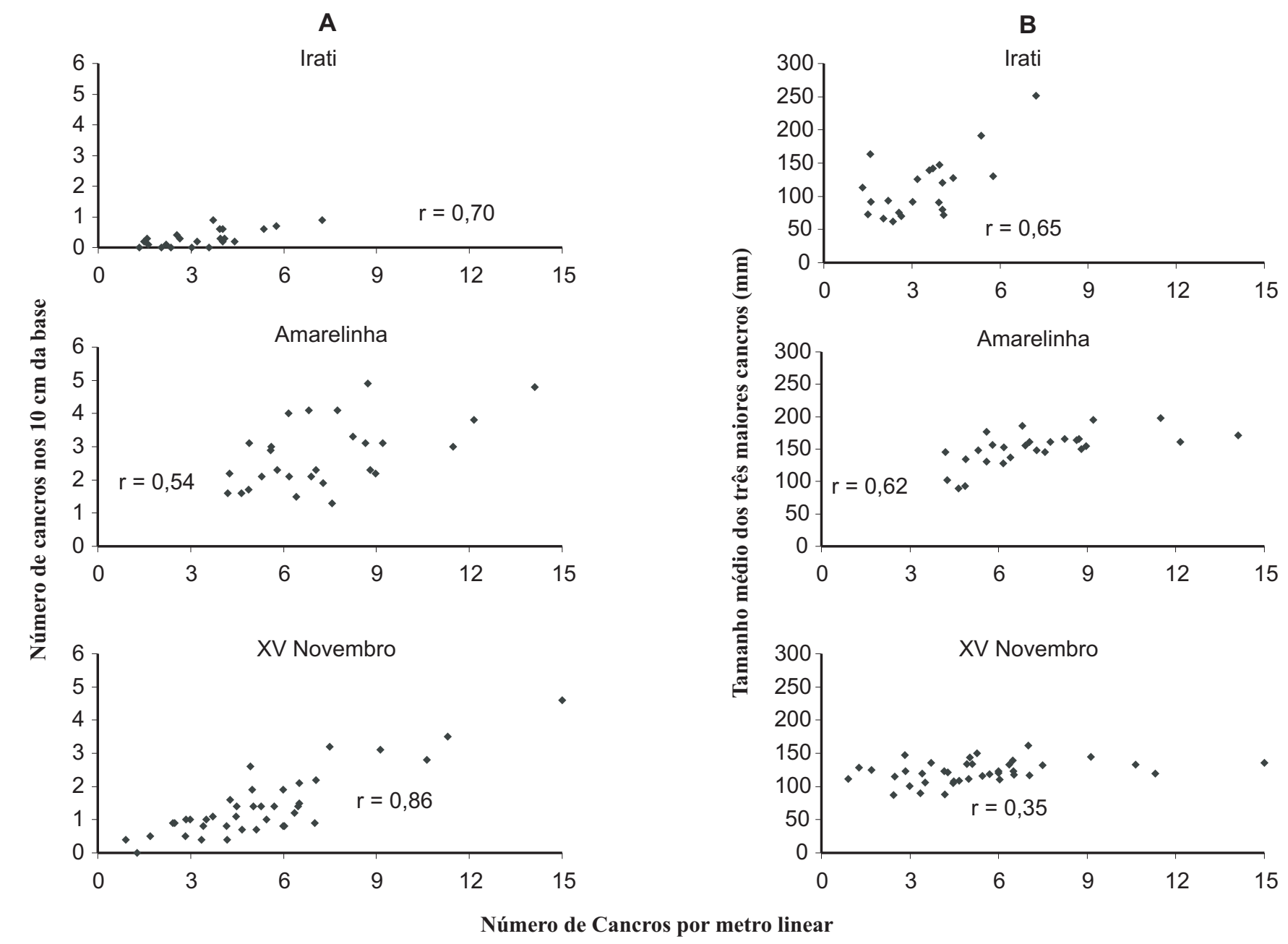

30 plantas. Em 2003, foi estabelecida uma amostragem aleatória de 10 plantas por cultivar.

d. Número de cancros por metro linear de ramo. Para os mesmos ramos e plantas citados na avaliação anterior, procedeu-se a contagem total dos cancros ao longo de todo o comprimento do ramo, obtendo-se o número de cancros por metro linear de ramo.

e. Tamanho dos três maiores cancros nos ramos. Para os mesmos ramos avaliados anteriormente, procedeu-se a mensuração do tamanho $(\mathrm{cm})$, no sentido do maior diâmetro, dos três maiores cancros por ramo.

O delineamento experimental empregado foi o inteiramente casualizado, sendo os dados transformados para " $(x+1)$, submetidos à análise de variância, e as médias, comparadas pelo teste Duncan $(P d " 0,05)$. Foram calculadas as seguintes correlações: número de cancros por metro linear de ramos versus número de cancros nos $10 \mathrm{~cm}$ da base dos ramos; e número de cancros por metro linear versus tamanho médio dos três maiores cancros. Estas correlações foram feitas isoladamente para cada cultivar em ambos os anos de observação, e para cada ano, independentemente das cultivares.

FIGURA 1 - Correlação entre: A) número de cancros por metro linear de ramo e número de cancros nos dez centímetros da base dos ramos; B) número de cancros por metro linear de ramo e tamanho médio dos três maiores cancros, nas cultivares Irati, Amarelinha e XV de Novembro, no ano de 2001. CEFET-PR, Unidade Sudoeste, Pato Branco - PR, 2005. 


\section{RESULTADOS E DISCUSSÃO}

Foram observadas diferenças significativas no nível de resistência à doença induzida por $X$. arboricula pv. pruni entre as cultivares estudadas (Tabela 1 ). A cultivar Irati apresentou-se como a mais resistente, seguida de 'XV de Novembro'. A cultivar Amarelinha foi a mais suscetível em todos os parâmetros analisados, diferindo significativamente das demais, exceto no critério de severidade da doença nas folhas, em relação à cultivar XV de Novembro (Tabela 1). Apesar de apresentar um número significativamente maior de lesões por folha que 'XV Novembro', a cv. Irati apresentou menor severidade, mostrando-se mais resistente que aquela (Tabela 1). Na cv. Irati, as lesões eram menores que nas outras cultivares, púrpuras, cujas bordas apresentavam, freqüentemente, necrose de tecidos, que impediam o avanço da colonização da bactéria, provocando a coalescência do tecido infectado, típico de reação de hipersensibilidade. Esta observação não é conclusiva e justifica um estudo que busque elucidar a genética da resistência na ameixeira.

Em 2001, 'Irati' foi menos suscetível que a cv. XV de Novembro, pois houve diferenças significativas entre essas cultivares em todos os parâmetros avaliados. Já em 2003, não foram observadas diferenças significativas entre 'Irati' e 'XV de Novembro' para o número médio de cancros nos $10 \mathrm{~cm}$ da base dos ramos e tamanho médio dos três maiores cancros.

Quanto às técnicas de avaliação de cancros em ramos de ameixeira, observou-se que, em 2001, quando as condições foram favoráveis à doença, todas as técnicas foram sensíveis para detectar diferenças no nível de resistência das cultivares. Porém, em 2003, quando as condições foram menos favoráveis, somente a contagem do número total de cancros mostrouse eficiente em detectar tais diferenças (Tabela 1).

As correlações entre o número de cancros por metro linear de ramos e o número de cancros nos $10 \mathrm{~cm}$ da base do ramo, para a cultivar Irati, foi de 0,70 nos anos em que foram feitas as avaliações. "Amarelinha" apresentou um coeficiente de correlação maior em 2003 ( $\mathrm{r}=0,90)$ que em 2001 ( $\mathrm{r}=0,54)$. Já para “XV Novembro", observou-se um coeficiente de correlação maior em 2001 ( $r=0,86)$ que em 2003 (r=0,50) (Figuras 1 e 2). Apesar dessas variações, quando os coeficientes de correlação foram feitos juntando-se os dados das três cultivares, dentro de cada ano de observação, obtiveram-se valores significativamente altos e idênticos $\left(\mathrm{r}=0,76^{* * *}\right)$ para 2001 e 2002. O elevado coeficiente de correlação entre o número de cancros por metro linear de ramo e o número de cancros nos $10 \mathrm{~cm}$ da base do ramo é um indicativo de que as duas técnicas podem ser utilizadas para classificar genótipos quanto ao grau de resistência a cancros de ramos induzidos por $X$. arboricola pv pruni. Porém, é mais vantajoso avaliar o número de cancros nos $10 \mathrm{~cm}$ da base do ramo porque o tempo gasto para a avaliação é menor.

As correlações entre o número de cancros por metro linear de ramo e o tamanho médio dos três maiores cancros foram bastante variáveis, especialmente para "XV de Novembro", que em 2003 apresentou um coeficiente de correlação negativo $(r=-0,60)$, diferindo do observado nas outras cultivares (Figuras 01 e 02 ). A avaliação da resistência de genótipos a cancros induzidos por Xanthomonas, por meio do tamanho médio dos três maiores cancros, foi pouco eficiente, apresentando baixa repetibilidade e condições de detectar diferenças, além do tempo dispendido para a execução ser bem superior às demais. A importância de um sistema de avaliação depende de sua repetibilidade, capacidade de detectar diferenças e tempo de execução a campo (Topp et al., 1991), características essas não observadas na técnica que se baseia no tamanho médio dos três maiores cancros.

O número de lesões por folha da cultivar Irati foi significativamente maior que da cultivar XV Novembro; no entanto, a severidade da doença foi significativamente menor (Tabela 1),
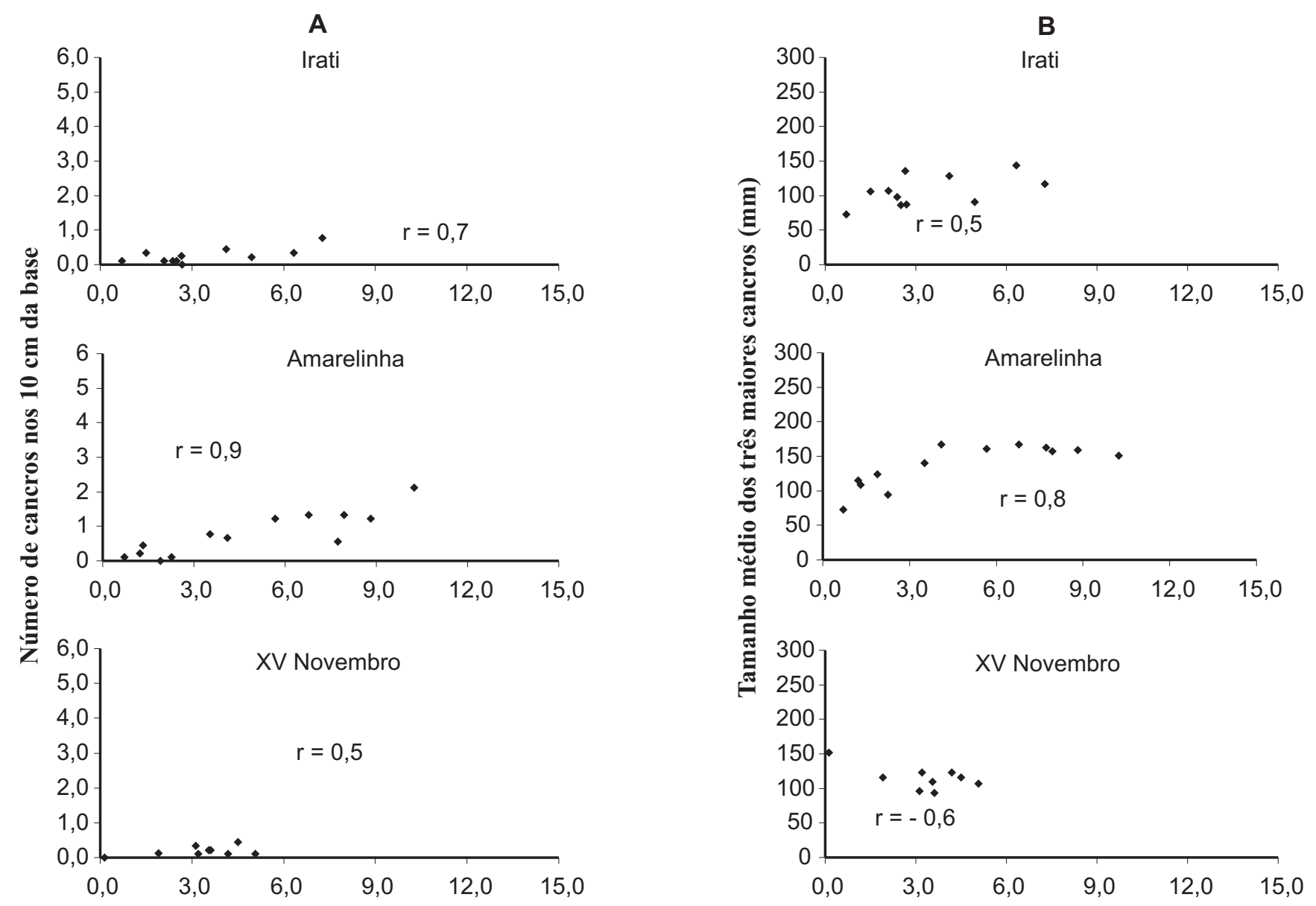

Número de Cancros por metro linear

FIGURA 2 - Correlação entre: A) número de cancros por metro linear de ramo e número de cancros nos dez centímetros da base dos ramos; B) número de cancros por metro linear de ramo e tamanho médio dos três maiores cancros, nas cultivares Irati, Amarelinha e XV de Novembro, no ano de 2003. CEFET-PR, Unidade Sudoeste, Pato Branco - PR, 2005. 
demonstrando divergências entre as técnicas utilizadas. A simples contagem do número de lesões por folha, mesmo sendo mais fácil e rápida que o cálculo da área afetada, pode não ser eficiente em quantificar resistência ou suscetibilidade de uma cultivar à doença foliar induzida por X. arborícola pv. Pruni, pois mais importante que se avaliar o número de lesões, é avaliar o quanto da área foliar está comprometida pelo patógeno. O coeficiente de variação foi menor para severidade da doença nas folhas que para o número médio de lesões por folha (Tabela 1), evidenciando maior confiabilidade dos resultados quando a técnica empregada para avaliar o nível de resistência for a severidade da doença, além de mostrar maior capacidade em detectar diferenças entre as cultivares.

O ganho genético em um programa de melhoramento é altamente afetado pelo método de avaliação devido à influência deste sobre a herdabilidade. Se a avaliação não for correta, corre-se o risco de descartar materiais genéticos resistentes a patógenos ou, ao contrário, considerar resistentes materiais suscetíveis. TOPP et al. (1991) compararam métodos de avaliação a campo com objetivo de determinar a aplicabilidade destes em programa de melhoramento. Os métodos comparados foram: medidas do número, tamanho e incidência de mancha bacteriana na folha, percentual da área afetada na folha e o tamanho do cancro nos ramos. Valores moderadamente elevados da herdabilidade no sentido amplo $(0,42$ a 0,58$)$ obtidos, considerando todos os métodos empregados, indicam que é possível aumentar o nível de resistência das cultivares à Xanthomonas, porém, com maior chance de sucesso em obter resistência nos ramos do que nas folhas (Topp et al., 1991). Scorza \& Sherman (1996) alertam sobre possíveis diferenças no grau de resistência de plantas jovens e adultas, bem como entre frutos e folhas. Para estes pesquisadores, o grau de resistência de uma estrutura não implica, necessariamente, o mesmo grau de resistência em outra estrutura. Estas suspeitas são estímulos para pesquisas futuras que busquem elucidá-las, um passo importante para a criação de cultivares mais resistentes a $X$. arboricola pv. pruni.

\section{CONCLUSÕES}

1. Das técnicas de avaliação utilizadas, a severidade da doença nas folhas foi mais eficiente que o número médio de lesões por folha. Para os ramos, as técnicas que consideram o número de cancros por metro linear e o número médio de cancros dos $10 \mathrm{~cm}$ da base são, ambas, eficientes, porém a última tem a vantagem de ser mais rápida e facilmente empregada.
2. A cultivar Irati apresentou a maior resistência à X. arboricola pv. pruni em comparação às cultivares Amarelinha e XV de Novembro.

\section{REFERÊNCIAS}

AMORIM, L. Avaliação de doenças. In: BERGAMIN FILHO, A.; KIMATI, H \& AMORIM, L. (Eds.). Manual de Fitopatologia: princípios e conceitos. 3. ed. São Paulo: Agronômica Ceres, 1995, v.1, p. 647-671.

FELICIANO, A. Bacteriose das prunoidae. I. Efeito da localização do pomar e do quebra-vento no desfolhamento prematuro do pessegueiro. In: CONGRESSO BRASILEIRO DE FRUTICULTURA, 2., 1973, Viçosa. Anais... Viçosa: SBF, 1973. v.2, p.455-462.

FORTES, J.F.; MARTINS, O.M. Sintomatologia e controle das principais doenças. In: MEDEIROS, C.A.B.; RASEIRA, M.C.B. A cultura do pessegueiro. Brasília: Embrapa-SPI; Pelotas: Embrapa-CPACT, 1998, p.243-264.

KEIL, H.L.; FOGLE, H.W. Orchard susceptibility of some apricot, peach, and plum cultivars and selections to Xanthomonas pruni. Fruit Varieties Journal. Urbana, v.28, p.16-19, 1974.

MOHAN, S.K.; NASCIMENTO, E.C.; KISHINO, A.Y.; CARVALHO, S.L.C. Observações sobre a ocorrência de bacteriose incitada por Xanthomonas pruni (E. F. Smith) Dowson, no Estado do Paraná. In: CONGRESSO BRASILEIRO DE FRUTICULTURA, 4. 1977, Salvador. Anais... Salvador: SBF, 1977, p.417-419.

NOGUEIRA, E.M.C.; RODRIGUES NETO, J. Xanthomonas campestris pv. pruni em Prunus spp. no Estado de são Paulo. O Biológico, São Paulo, v.48, n.9, p.227-229, 1982.

ROM, R.C. \& MOORE, J.N. Peach cultivar situation in the Midwest and Central South. Fruit Varieties Journal, Urbana, v.33, n. 1, p.25-29, 1979.

SCORZA, R.; SHERMAN, W.B. Peaches. In: JANICK, J.; MOORE, J.N. Fruit breeding. New York: John Wiley \& Sons, Inc, 1996, p.325-440.

TOPP, B.L.; SHERMAN, W.B.; STALL, R.E. Comparison of rating methods for bacterial spot resistance in Japanese-type plum. Fruit Varieties Journal, Urbana, v.45, n.2, p.70-74, 1991.

WERNER, D.J.; RITCHIE, D.F.; CAIN, D.W.; ZEHR, E.I. Susceptibility of peaches and nectarines, plant introductions, and other Prunus to bacterial spot. HortScience, Alexandria, v.21, n.1, p.127-130, 1986. 